\title{
Inhibition of Matrix Metalloproteinases Enhances In Vitro Repair of the Meniscus
}

\author{
Amy L. McNulty PhD, J. Brice Weinberg MD, \\ Farshid Guilak PhD
}

Received: 26 March 2008/Accepted: 14 October 2008/Published online: 31 October 2008

(C) The Association of Bone and Joint Surgeons 2008

\begin{abstract}
Damage or injury of the meniscus is associated with onset and progression of knee osteoarthritis (OA). The intrinsic repair capacity of the meniscus is inhibited by inflammatory cytokines, such as interleukin-1 (IL-1). Using an in vitro meniscal repair model system, we examined the hypothesis that inhibition of matrix metalloproteinases (MMPs) in the presence of IL-1 will enhance repair of meniscal lesions. Integrative repair of the meniscus was examined between two concentric explants cultured with IL-1 and various MMP inhibitors for 14 days. Throughout the culture period, we assessed total specific MMP activity in the media. At harvest, biomechanical testing to assess the strength of repair and histologic staining were performed. IL-1 decreased the shear strength of repair, as compared with control explants. In the presence of IL-1, the broad-spectrum MMP inhibitor GM 6001 decreased the MMP activity in the media, increased the shear strength of
\end{abstract}

One or more of the authors have received funding from the Arthritis Foundation (ALM, FG), VA Rehabilitation Research Service Award (JBW), and NIH Grants AR50245 (FG), AG15768 (FG), AR48182 (FG), AR48852 (FG), and AR55434 (ALM).

A. L. McNulty, F. Guilak ( $ه)$

Department of Surgery, Duke University Medical Center, 375 MSRB, Box 3093, Durham, NC 27710, USA

e-mail: guilak@duke.edu

\section{J. B. Weinberg}

Department of Medicine, Duke University Medical Center,

Durham, NC, USA

J. B. Weinberg

VA Medical Center, Durham, NC, USA

F. Guilak

Department of Biomedical Engineering, Duke University, Durham, NC, USA repair, and enhanced tissue repair in the interface. However, individual MMP inhibitors did not alter the shear strength of repair in either the presence or absence of IL-1. These findings suggest IL-1 may inhibit meniscal repair through upregulation of MMPs, but inhibition of multiple MMPs may be necessary to promote integrative meniscal repair.

\section{Introduction}

Menisci are C-shaped fibrocartilaginous tissues situated between the femoral condyles and tibial plateau in the knee. The menisci are required for normal biomechanical function of the knee, playing important roles in load bearing, shock absorption, joint congruity, and joint stability $[1,39,59]$. The meniscus is divided into two distinct regions, depending on the distance from the peripheral edge. The outer $1 / 3$, or the red-red zone, of the meniscus is characterized by fibroblast-like cells [23, 53] and the presence of vessels [3] and Type I collagen [12, 19, 33]. In contrast, the inner region, or the white-white zone, of the meniscus is avascular [3], has a higher aggrecan content than the outer zone, and consists of fibrochondrocyte-like cells [23, 53] and Types I and II collagen [12, 33].

Meniscal tears are common knee injuries, resulting in approximately 850,000 surgeries per year in the United States and at least twice as many worldwide [5]. In addition to the pain and loss of function associated with a meniscal tear, damage and degenerative changes in the meniscus ultimately lead to loss of cartilage and development of OA $[13,29,49,60]$, with $2 / 3$ of patients having radiographic knee OA develop within 5 to 15 years [37]. Current clinical treatments seek to promote repair of meniscal lesions and 
preserve the meniscus whenever possible. Lesions in the outer, vascularized region of the meniscus generally have the capacity to heal; however, tears in the inner avascular region of the meniscus have negligible repair presumably owing to lack of vasculature [4]. However, in an in vitro model of repair in which the effects of the vasculature are eliminated, meniscal tissue from the inner and outer regions has similar intrinsic repair capacity [25]. In this model system, once the effect of vasculature is removed from the equation, then other factors can be identified that promote meniscal healing and ultimately could be translated to the intraarticular conditions required for repair in vivo.

Increased levels of inflammatory cytokines, in particular IL-1, are observed in injured and degenerate joints [22, 27, 32]. In turn, these increased levels of IL-1 can suppress matrix biosynthesis and increase enzymatic degradation in joint tissues. Specifically, IL-1 increases the expression and activity of MMPs in meniscal cells and explants [11, 21, 58]. Additionally, IL-1 dose-dependently decreases the interfacial shear strength of meniscal repair, suppresses cell accumulation, and inhibits tissue formation in the meniscal repair interface $[24,41]$. Of particular interest is the finding that acute exposure of meniscal tissue to IL-1 for only 1 or 3 days is sufficient to suppress tissue repair for up to 4 weeks [58]. This IL-1 suppression of meniscal shear strength is correlated with an increase in MMP activity in the media, with approximately $37 \%$ of the variability in the shear strength attributable to MMP activity. Although the general effects of IL-1 on meniscal repair have been well established, the mechanism(s) by which IL-1 inhibits meniscal repair has yet to be determined.

MMPs are a family of enzymes collectively able to cleave all components of the extracellular matrix. MMPs are divided into four subfamilies: stromelysins, gelatinases, membrane-type MMPs, and collagenases [42, 45]. Only the collagenases (MMP-1 [55], MMP-8, MMP-13 [34, 35, 44, 48]) and membrane type 1 MMP [46] are able to cleave the intact triple helical collagens [6]. After the collagenase cleavage of collagen, the fibers denature and become susceptible to cleavage by the gelatinases, stromelysins, and many other proteases [8]. Therefore, collagenase expression is believed to be a rate-limiting step in collagen degradation [42].

Meniscal cells express MMP-1 (collagenase 1), MMP-2 (gelatinase A), MMP-3 (stromelysin 1), MMP-8 (collagenase 2), MMP-9 (gelatinase B), and MMP-13 (collagenase $3)[14,26,53,61]$. In particular, the outer zone of the meniscus expresses higher levels of MMP-2 and MMP-3 than the inner zone [53], and static compression upregulates MMP-1 mRNA in the outer zone [52]. In patients with a meniscal injury, MMP-3 levels are elevated 30- to 40fold, and tissue inhibitor of metalloproteinase (TIMP)-1 levels are increased 10-fold in the synovial fluid within 24 hours of injury [37]. Synovial fluid MMP-3 levels remain elevated 10-fold and the TIMP-1 concentrations are increased three- to fourfold for at least 20 years postinjury, resulting in a net excess of free enzyme in the joint [37]. Additionally, after ACL transection in rabbits, expression of MMP-1 and MMP-13 in the meniscus is elevated at 2 weeks and remains elevated to 9 weeks postsurgery [7]. An MMP selective inhibitor and a nonselective inhibitor (which blocks MMPs and aggrecanases) decrease glycosaminoglycan release and improve the mechanical function of IL-1-treated bovine fibrocartilage explants [57]. However, an aggrecanase selective inhibitor does not affect glycosaminoglycan release or mechanical function, suggesting MMPs mediate meniscal degradation in response to IL-1. Nonetheless, the role of MMPs in integrative meniscal repair is not fully understood.

We tested the hypotheses that inhibition of MMPs in the presence of IL-1 would decrease the activity of MMPs, increase the shear strength of integrative repair, and enhance tissue repair at the interface of meniscal lesions.

\section{Materials and Methods}

To test the hypotheses, we used an in vitro meniscal repair model system [24, 25, 41, 58] to examine the effects of MMP inhibitors on meniscal healing in the presence of IL-1. Explants were cultured with control media, IL- $1 \alpha$, IL- $1 \alpha$ and MMP inhibitors, and MMP inhibitors alone for 14 days. Medial menisci were harvested from porcine knees and four explants were isolated from each meniscus and cultured in different treatment groups. To determine the effect of MMP inhibitors on MMP activity, a quenched fluorogenic peptide was used to measure activity in the culture media every 3 days. At the end of culture, meniscal healing was investigated using a push-out test and tissue repair at the interface was assessed by histologic staining. Based on previous work [58], power calculations were performed to determine the sample sizes necessary to show meaningful biologic effects. For mechanical testing, a sample size of $\mathrm{n}=7$ provides $75 \%$ power to detect a change of $50 \%$ or greater in the shear strength, using STATISTICA $^{\circledR} 7.0$ (StatSoft Inc, Tulsa, OK) and a oneway ANOVA. For MMP activity, a $30 \%$ or greater change in the activity would be detectable with $\mathrm{n}=9$ and provides 95\% power to detect treatment differences, using a oneway ANOVA.

Medial menisci were harvested from 2- to 3-year-old skeletally mature female pig knees obtained from a local abattoir. Cylindrical explants were harvested from the femoral surface of the outer $2 / 3$ of the meniscus, using an 8-mm biopsy punch (Miltex, Inc, York, PA) oriented 
perpendicular to the meniscal surface (Fig. 1). To simulate a full-thickness meniscal tear, a central core of $4 \mathrm{~mm}$ was punched completely through each explant, using a biopsy punch (Miltex, Inc) and immediately reinserted in the same orientation. Explants then were cut from the meniscus at a thickness of $3 \mathrm{~mm}$, using a scalpel blade oriented parallel to the meniscal surface. Explants were incubated in Dulbecco's Modified Eagle's Medium (DMEM; Invitrogen, Carlsbad, CA), containing $1000 \mathrm{U} / \mathrm{mL}$ penicillin/streptomycin (Invitrogen) for 1 hour at $37^{\circ} \mathrm{C}$ on plates coated with $2 \%$ agarose, to prevent cell outgrowth and proliferation on the plates. Medium was removed, and explants then were cultured in DMEM containing 10\% heat-inactivated fetal bovine serum (HyClone, Logan, UT), $0.1 \mathrm{mmol} / \mathrm{L}$ nonessential amino acids (Invitrogen), $10 \mathrm{mmol} / \mathrm{L}$ HEPES buffer solution (Invitrogen), $100 \mathrm{U} / \mathrm{mL}$ penicillin/streptomycin, and $37.5 \mu \mathrm{g} / \mathrm{mL}$ L-ascorbic acid 2-phosphate (SigmaAldrich Corp, St Louis, $\mathrm{MO}$ ) at $37^{\circ} \mathrm{C}$ and $5 \% \mathrm{CO}_{2}$. Media were collected and replaced every 3 days.

Immediately after harvest, explants $(\mathrm{n} \geq 7$ per treatment group each from different porcine menisci) were cultured for 14 days and treated with $100 \mathrm{pg} / \mathrm{mL}$ recombinant
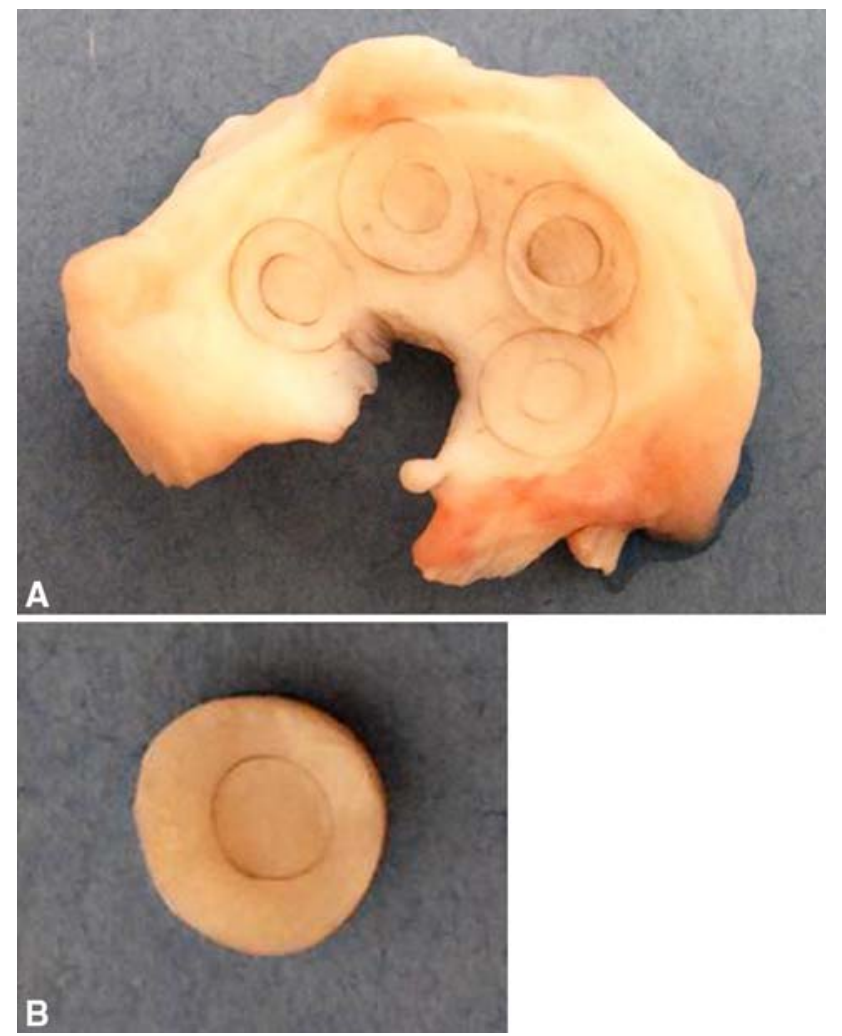

Fig. 1A-B (A) A medial meniscus shows the location of repair model explants harvested from the tissue. An 8-mm biopsy punch oriented normal to the meniscal surface was used to harvest explants. A 4-mm biopsy punch was used to simulate a full-thickness tear through the central portion of each explant. (B) Repair model explants then were isolated from the meniscus and cultured. porcine IL-1 $\alpha$ [41] (R\&D Systems, Minneapolis, MN), $100 \mathrm{pg} / \mathrm{mL}$ IL-1 in the presence of different MMP inhibitors (Table 1), and MMP inhibitors alone. Although there are two isoforms of IL-1 (IL- $1 \alpha$ and IL- $1 \beta$ ), both isoforms have the same potency. IL- $1 \alpha$ is believed to be the more prominent factor early during the inflammatory process, whereas IL-1 $\beta$ is the more dominant isoform in advanced inflammation [54]. Thus, we focused on the effects of IL$1 \alpha$, as the early-acting proinflammatory isoform. Previously, we tested this model system at 14,28 , and 42 days in culture and observed a time-dependent increase in interfacial repair with trends at 14 days similar to those observed at later times [41].

To test the effects of MMP inhibitors on the repair of meniscal lesions in the presence and absence of IL-1, explants were incubated with the following inhibitors (all from EMD Biosciences, San Diego, CA): $200 \mathrm{ng} / \mathrm{mL}$ GM 6001, which is a broad-spectrum MMP inhibitor; $600 \mathrm{ng} /$ $\mathrm{mL}$ MMP-2 inhibitor I; $600 \mathrm{ng} / \mathrm{mL}$ MMP-2/MMP-9 inhibitor I; $600 \mathrm{ng} / \mathrm{mL}$ MMP-3 inhibitor II; $600 \mathrm{ng} / \mathrm{mL}$ MMP-8 inhibitor I; and $600 \mathrm{ng} / \mathrm{mL}$ MMP-13 inhibitor. In addition, to control for nonspecific activity of GM 6001 or the MMP-8 inhibitor, samples were incubated with $200 \mathrm{ng} /$ $\mathrm{mL}$ GM 6001 negative control or $600 \mathrm{ng} / \mathrm{mL}$ MMP-8 inhibitor I negative control, respectively. The concentrations used in this study were based on a dose response curve of the MMP inhibitors on media from IL-1-treated meniscal explants to determine the lowest concentration of inhibitor that maximally inhibited MMP activity in the media. Table 1 lists the specificities and activity of each of these inhibitors. In this study, the IL-1 and MMP inhibitors were administered simultaneously, as a model for injury when patients may be treated immediately after a meniscal tear.

A fluorescence-based assay was used to measure total specific MMP activity in the culture media, as described previously [58]. Media samples were diluted twofold in

Table 1. MMP inhibitor specificity and selectivity

\begin{tabular}{ll}
\hline Enzyme & Inhibitor \\
\hline MMP-1 & GM $6001\left(\mathrm{~K}_{\mathrm{i}}=0.4 \mathrm{nmol} / \mathrm{L}\right)$ \\
MMP-2 & GM $6001\left(\mathrm{~K}_{\mathrm{i}}=0.5 \mathrm{nmol} / \mathrm{L}\right)$ \\
& MMP-2 inhibitor I $\left(\mathrm{K}_{\mathrm{i}}=1.7 \mu \mathrm{mol} / \mathrm{L}\right)$ \\
& MMP-2/MMP-9 inhibitor I $\left(\mathrm{IC}_{50}=310 \mathrm{nmol} / \mathrm{L}\right)$ \\
MMP-3 & GM 6001 $\left(\mathrm{K}_{\mathrm{i}}=27 \mathrm{nmol} / \mathrm{L}\right)$ \\
& MMP-3 inhibitor II $\left(\mathrm{K}_{\mathrm{i}}=130 \mathrm{nmol} / \mathrm{L}\right)$ \\
MMP-8 & GM 6001 $\left(\mathrm{K}_{\mathrm{i}}=0.1 \mathrm{nmol} / \mathrm{L}\right)$ \\
& MMP-8 inhibitor I $\left(\mathrm{IC}_{50}=4 \mathrm{nmol} / \mathrm{L}\right)$ \\
MMP-9 & GM 6001 $\left(\mathrm{K}_{\mathrm{i}}=0.2 \mathrm{nmol} / \mathrm{L}\right)$ \\
& MMP-2/MMP-9 inhibitor I $\left(\mathrm{IC}_{50}=240 \mathrm{nmol} / \mathrm{L}\right)$ \\
MMP-13 & MMP-13 inhibitor $\left(\mathrm{IC}_{50}=8 \mathrm{nmol} / \mathrm{L}\right)$ \\
\hline
\end{tabular}


assay buffer consisting of $200 \mathrm{mmol} / \mathrm{L} \mathrm{NaCl}, 50 \mathrm{mmol} / \mathrm{L}$ Tris, $5 \mathrm{mmol} / \mathrm{L} \mathrm{CaCl}_{2}, 10 \mu \mathrm{mol} / \mathrm{L} \mathrm{ZnSO}_{4}, 0.01 \% \mathrm{Brij}^{\circledR} 35$, $\mathrm{pH} 7.5$ [16], and $20 \mu \mathrm{mol} / \mathrm{L}$ of the quenched fluorogenic substrate Dab-Gly-Pro-Leu-Gly-Met-Arg-Gly-Lys-Flu [16, 47] (Sigma-Aldrich). Media samples were run in duplicate, with one replicate incubated with $25 \mathrm{ng} / \mathrm{mL}$ GM 6001 and the other incubated with $25 \mathrm{ng} / \mathrm{mL}$ GM 6001 negative control. Samples were incubated for 2 hours in the dark at $37^{\circ} \mathrm{C}$. Fluorescence was measured at $485-\mathrm{nm}$ excitation and 535-nm emission using a GENios ${ }^{\mathrm{TM}}$ plate reader (Phenix Research Products, Hayward, CA). The difference in measured fluorescence between medium samples incubated with GM 6001 negative control and GM 6001 (this correction removes any background or nonspecific activity) was normalized by the wet weight of the tissue and used to calculate the total specific MMP activity for each explant.

After 14 days of culture, the interfacial shear strength of repair between the inner core and outer ring was determined using a push-out test as described previously [24, 25, 41, 58]. Explants (8-mm outer ring with integrated 4-mm inner core) were placed in a custom-built testing fixture consisting of a suspended cup with a central 5-mm hole in the base (Fig. 2). Using a materials testing system (ElectroForce ${ }^{\circledR}$ 3200; Bose-EnduraTEC Corp, Eden Prairie, $\mathrm{MN}$ ), a 3-mm-diameter rod was displaced at a constant rate of $0.0833 \mathrm{~mm}$ per second until the inner core was

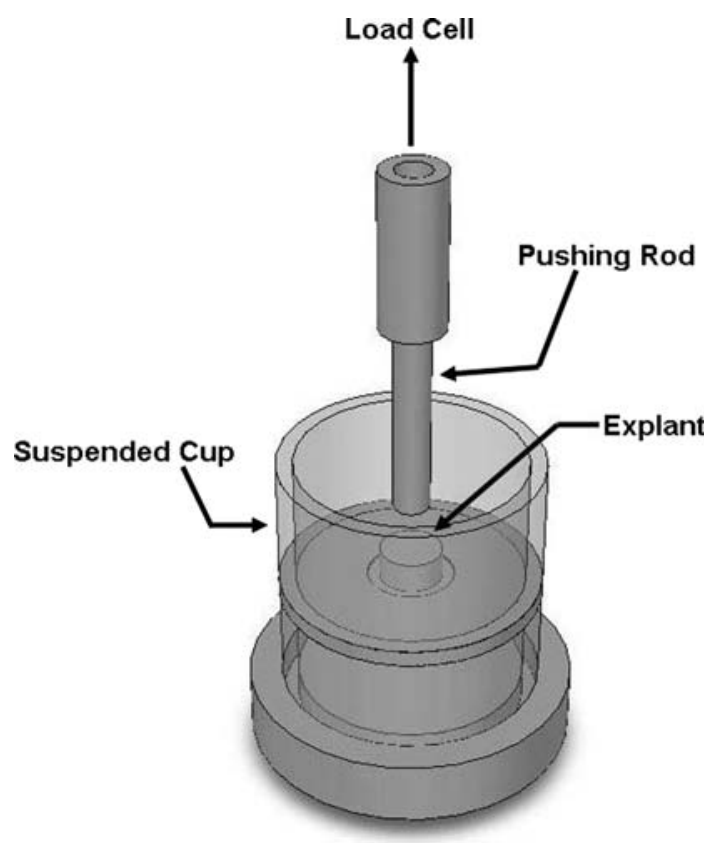

Fig. 2 A schematic of the push-out test fixture is shown. Meniscal explants were placed in the custom-built fixture with the inner core centered over the 5-mm hole in the base of the suspended cup, allowing it to be freely pushed out of the outer ring with the 3-mmdiameter pushing rod. A load cell was used to acquire force measurements throughout the duration of the test. pushed fully through the outer ring. Force measurements were acquired throughout the duration of the test by a highresolution 500-g load cell with an accuracy of $0.1 \%$ (Sensotec Model 31/6775-06; Honeywell Sensotec, Columbus, $\mathrm{OH})$. After testing, sample thickness was measured using a custom-built vision system consisting of a black and white digital video camera (Sony Electronics, Park Ridge, NJ) and a 44-mm video lens (Infinity, Boulder, $\mathrm{CO})$. Images were acquired and analyzed using LabVIEW $^{\mathrm{TM}}$ Vision Builder AI for Windows ${ }^{\circledR}$ (National Instruments Corp, Austin, TX). The peak force at failure was normalized by the area of the interface between the outer ring and inner core to determine the interfacial shear strength.

After 14 days in culture, meniscal explants were processed for histologic staining. Samples were fixed overnight at $4^{\circ} \mathrm{C}$ in $4 \%$ paraformaldehyde (Electron Microscopy Sciences, Hatfield, PA) and $100 \mathrm{mmol} / \mathrm{L}$ sodium cacodylate trihydrate (Electron Microscopy Sciences), $\mathrm{pH}$ 7.4. Samples were dehydrated in ethanol, infiltrated with xylene, and paraffin embedded. Sections $(10 \mu \mathrm{m})$ were stained with Harris hematoxylin with glacial acetic acid (Poly Scientific, Bay Shore, NY), 0.02\% aqueous fast green (Sigma-Aldrich), and Accustain ${ }^{\circledR}$ safranin O solution (Sigma-Aldrich).

Statistical analyses of the shear strength and MMP activity data were performed using STATISTICA ${ }^{\circledR}$ 7.0. A one-way ANOVA and the Newman-Keuls post hoc test were used to identify differences $(\alpha=0.05)$ between treatment groups.

\section{Results}

The MMP activity in the media from each meniscal repair model explant was measured throughout the culture period (Fig. 3). With time in culture, there was a slight increase in MMP activity in the media from control explants. IL-1 treatment progressively increased MMP activity with time in culture. Additionally, MMP activity in samples treated with IL-1 and the GM 6001 negative control inhibitor was similar to the activity measured in the IL-1-treated explants (data not shown). However, in the presence of IL-1, the broad-spectrum MMP inhibitor GM 6001 suppressed ( $p$ $\leq 0.00016$ ) MMP activity (Fig. 3A). Additionally, GM 6001 alone diminished MMP activity to background levels. In either the presence or absence of IL-1, treatment with an MMP-2 inhibitor (Fig. 3B) or an MMP-2/MMP-9 inhibitor (Fig. 3C) did not alter the overall MMP activity, as compared with IL-1 treatment or control, respectively. However, treatment with an MMP-3 inhibitor decreased ( $\mathrm{p} \leq 0.00055)$ the IL-1-induced MMP activity in the media from meniscal repair model explants (Fig. 3D). 

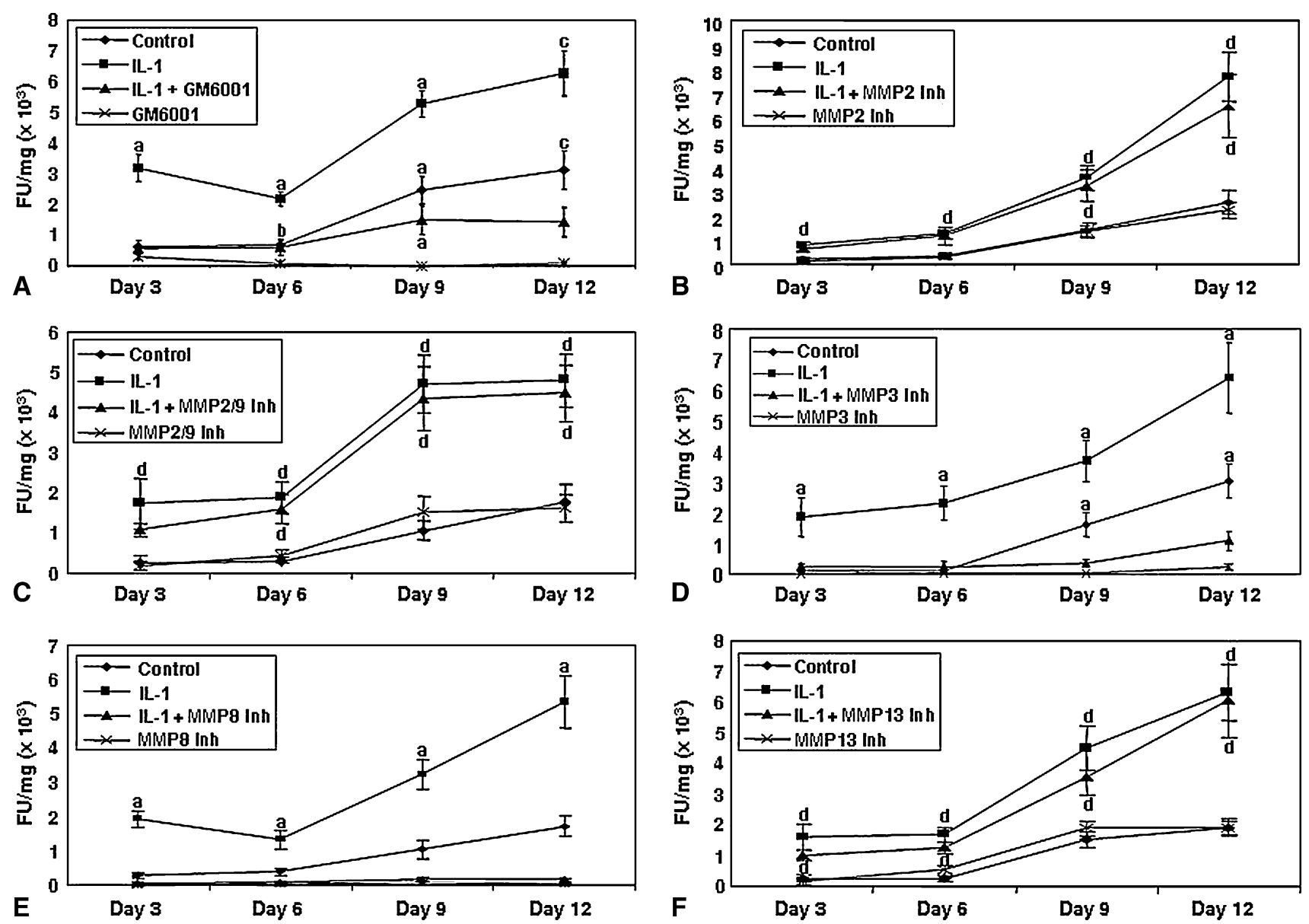

Fig. 3A-F Total specific MMP activity in the culture media with time was measured using a quenched fluorescent substrate $(n=10$ 12 samples per treatment group). The bars indicate the mean fluorescence units normalized by the wet weight of the meniscal tissue (FU/mg) \pm standard error. (A) GM 6001 inhibits IL-1mediated MMP activity. The gelatinase inhibitors (B) MMP-2 inhibitor (Inh) and (C) MMP-2/9 inhibitor do not decrease IL-1-

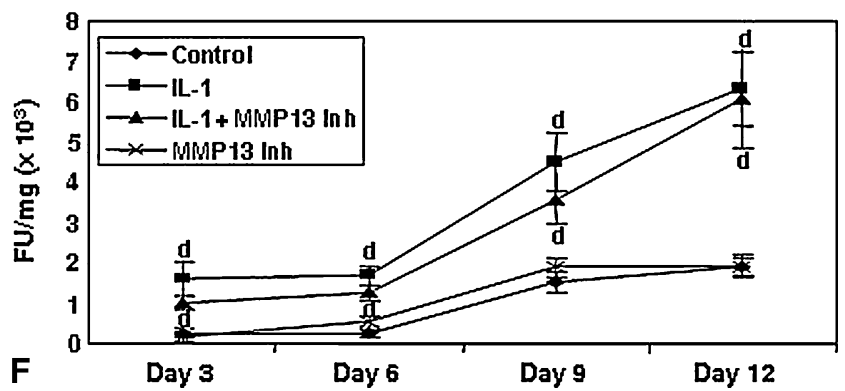

mediated MMP activity. (D) Suppression of MMP-3 activity decreases IL-1-mediated MMP activity. Suppression of (E) MMP-8 but not (F) MMP-13 decreases IL-1-mediated MMP activity. $\mathrm{a}=\mathrm{p} \leq 0.034$ compared with all other treatments; $\mathrm{b}=\mathrm{p}=0.0047$ compared with GM 6001; $c=p \leq 0.00033$ compared with IL-1 + GM 6001 and GM 6001; d = p $\leq 0.026$ compared with control and inhibitor.

Additionally, treatment with an MMP-3 inhibitor in the absence of IL-1 decreased the MMP activity to control levels. Inhibition of MMP-8 also diminished ( $\mathrm{p} \leq 0.00018$ ) total MMP activity to baseline levels in the presence of IL-1 (Fig. 3E). The inclusion of the MMP-8 negative control inhibitor in the presence of IL-1 resulted in total MMP activity consistent with IL-1 treatment alone (data not shown). However, in either the presence or absence of IL-1, suppression of MMP-13 did not alter the total MMP activity compared with IL-1 treatment alone or control, respectively (Fig. 3F).

Although IL-1 increased the MMP activity in the media, it decreased $(\mathrm{p} \leq 0.00047)$ the shear strength of repair, as compared with control explants (Figs. 4, 5, 6, 7). In the presence of IL-1, inclusion of the broad-spectrum MMP inhibitor GM 6001 increased $(p=0.043)$ the shear strength of repair 2.3-fold over IL-1-treated explants alone

(Fig. 4). However, there was no difference in the shear strength of repair in explants treated with IL-1 versus IL-1 with the GM 6001 negative control. In the presence of IL-1, inhibitors of MMP-2, MMP-2/9, MMP-3, MMP-8, or MMP-13 activity had no effect on the shear strength (Figs. 5-7). In addition, the MMP-8 negative control inhibitor in the presence of IL-1 had no effect on the shear strength compared with IL-1 treatment alone (data not shown). The interfacial shear strength of repair also was determined for each of the MMP inhibitors alone (Fig. 8). None of the MMP inhibitors used in these studies altered the interfacial shear strength of repair, as compared with control samples.

Histologic analyses of control meniscal explants revealed healing of the meniscal defect at the interface during the 14 days in culture (Fig. 9). At Day 0, the interface was clearly visible between the inner core and the 


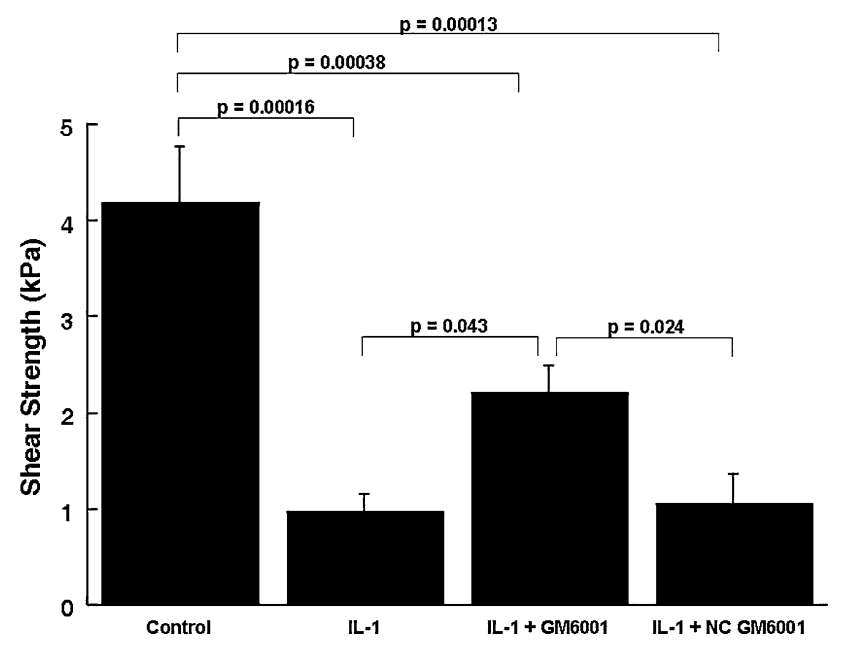

Fig. 4 GM 6001 increases meniscal interfacial shear strength in the presence of IL-1. The interfacial shear strength of repair was measured after treatment of meniscal repair model explants with control media, $100 \mathrm{pg} / \mathrm{mL}$ IL-1, $100 \mathrm{pg} / \mathrm{mL}$ IL-1 and $200 \mathrm{ng} / \mathrm{mL}$ GM 6001, and $100 \mathrm{pg} / \mathrm{mL}$ IL-1 and $200 \mathrm{ng} / \mathrm{mL}$ GM 6001 negative control (NC) for 14 days ( $\mathrm{n}=9-11$ explants per treatment group). The bars indicate the mean + standard error.

outer ring of the meniscal repair explants. With time, the gap in the interface was repaired with an extracellular matrix that stained strongly with fast green, revealing the presence of collagen fibers. However, no visible tissue repair was detected in explants treated with either IL-1 or IL-1 and the specific MMP inhibitors. The explants treated with IL-1 and GM 6001 showed increased tissue repair at the interface. Additionally, meniscal repair model explants treated with the MMP inhibitors alone also showed collagen tissue repair at the interface. Overall, the interfaces of control and MMP inhibitor-treated samples contained more cells that presumably were mediating the increased tissue

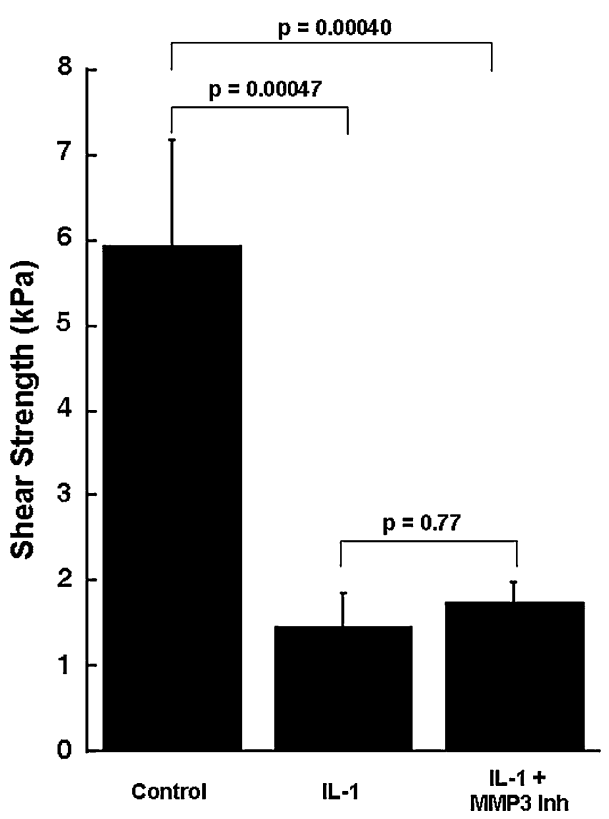

Fig. 6 Inhibition of MMP-3 activity in the presence of IL-1 does not increase meniscal interfacial shear strength. The interfacial shear strength of repair was measured after treatment of meniscal repair model explants with control media, $100 \mathrm{pg} / \mathrm{mL}$ IL-1, and $100 \mathrm{pg} / \mathrm{mL}$ IL-1 and $600 \mathrm{ng} /$ mL MMP-3 inhibitor (Inh) for 14 days $(\mathrm{n}=9-11$ explants per treatment group). The bars indicate the mean + standard error.

formation. However, the inclusion of IL-1 in the culture media, alone or in the presence of MMP inhibitors, diminished the cell accumulation in the repair interfaces.

\section{Discussion}

Joint injury and degeneration lead to upregulation of inflammatory cytokines in the synovial fluid [22, 27, 32,
Fig. 5A-B Inhibition of gelatinases, (A) MMP-2 and (B) MMP$2 / 9$, in the presence of IL- 1 does not increase meniscal interfacial shear strength. The interfacial shear strength of repair was measured after treatment of meniscal repair model explants with (A) control media, $100 \mathrm{pg} / \mathrm{mL}$ IL-1, and $100 \mathrm{pg} / \mathrm{mL}$ IL-1 and $600 \mathrm{ng} /$ mL MMP-2 inhibitor (Inh) or (B) control media, $100 \mathrm{pg} / \mathrm{mL}$ IL-1, and $100 \mathrm{pg} / \mathrm{mL} \mathrm{IL}-1$ and $600 \mathrm{ng} /$ $\mathrm{mL}$ MMP-2/9 inhibitor for 14 days $(\mathrm{n}=7-10$ explants per treatment group). The bars indicate the mean + standard error
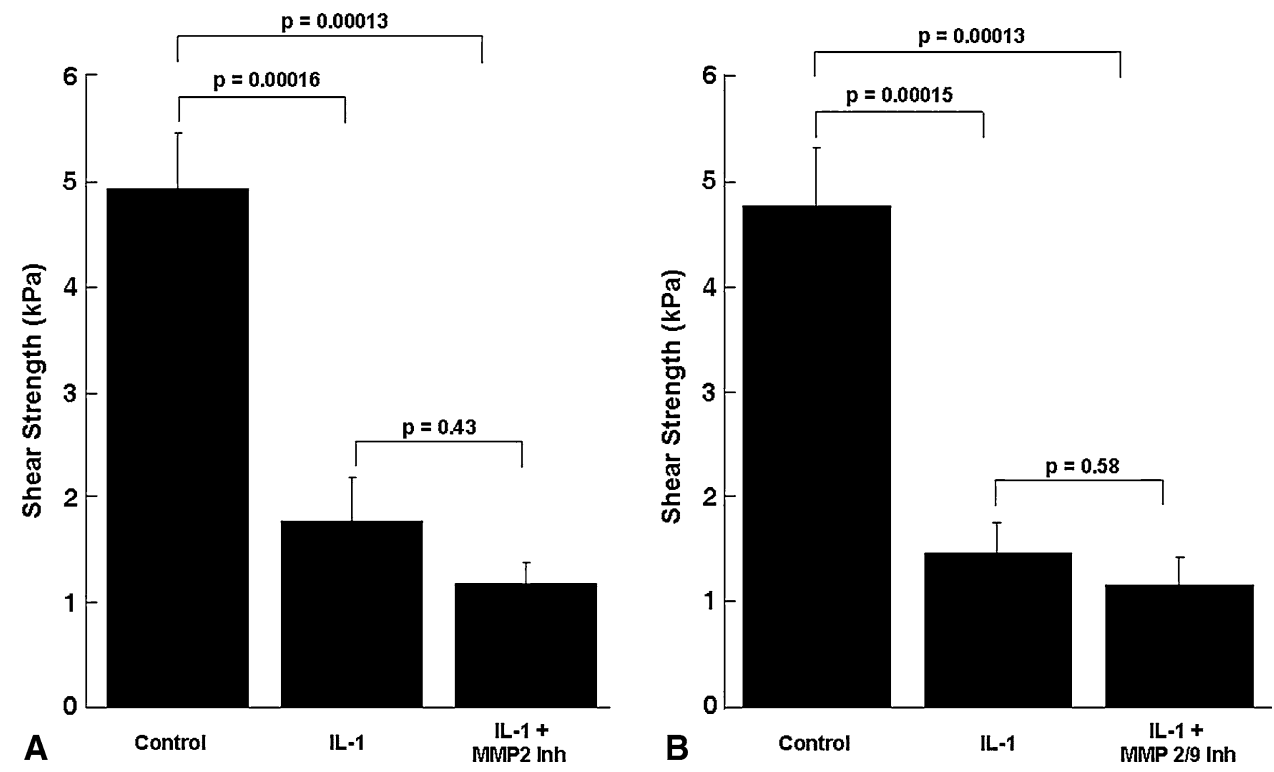
Fig. 7A-B Inhibition of collagenases, (A) MMP-8 and (B) MMP-13, in the presence of IL-1 does not increase meniscal interfacial shear strength. The interfacial shear strength of repair was measured after treatment of meniscal repair model explants with (A) control media, $100 \mathrm{pg} /$ $\mathrm{mL}$ IL-1, and $100 \mathrm{pg} / \mathrm{mL}$ IL-1 and $600 \mathrm{ng} / \mathrm{mL}$ MMP-8 inhibitor (Inh) and (B) control media, $100 \mathrm{pg} / \mathrm{mL}$ IL-1, and $100 \mathrm{pg} / \mathrm{mL}$ IL-1 and $600 \mathrm{ng} / \mathrm{mL}$ MMP-13 inhibitor for 14 days $(n=8-10$ explants per treatment group). The bars indicate the mean + standard error.
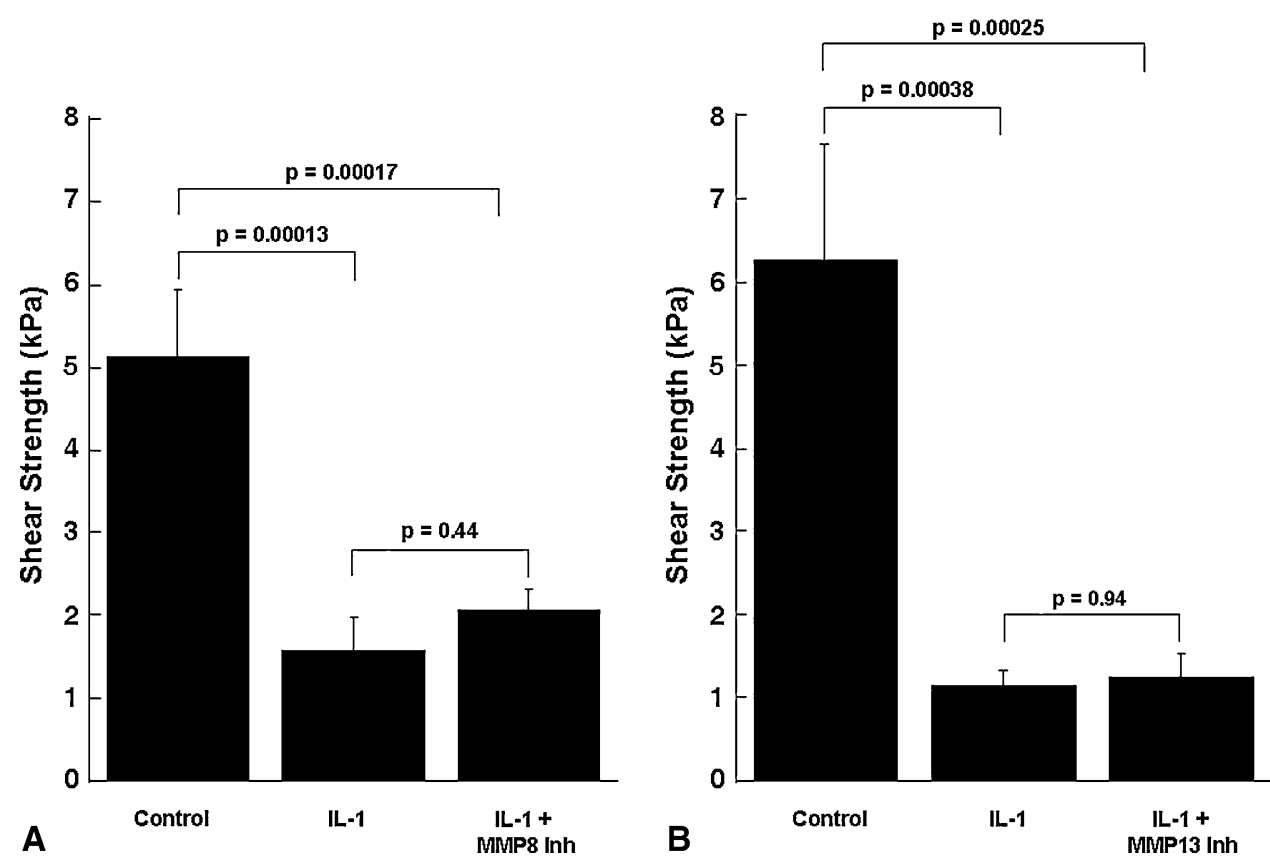

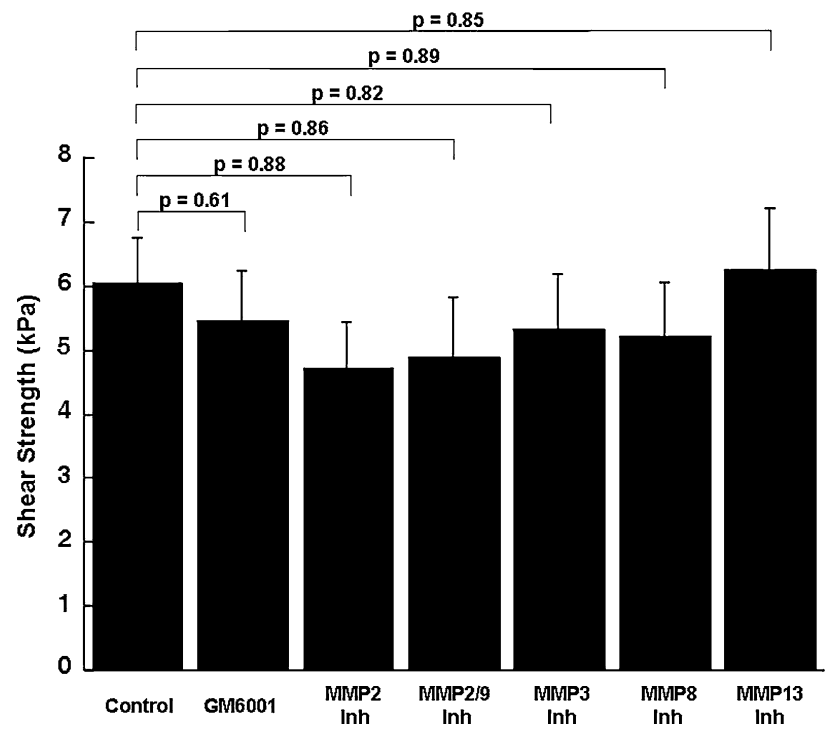

Fig. 8 MMP inhibitors do not alter the meniscal interfacial shear strength of repair. The interfacial shear strength of repair was measured after treatment of meniscal repair model explants with control media, $200 \mathrm{ng} / \mathrm{mL}$ GM 6001, $600 \mathrm{ng} / \mathrm{mL}$ MMP-2 inhibitor (Inh), $600 \mathrm{ng} / \mathrm{mL}$ MMP-2/9 inhibitor, $600 \mathrm{ng} / \mathrm{mL}$ MMP-3 inhibitor, $600 \mathrm{ng} / \mathrm{mL}$ MMP-8 inhibitor, and $600 \mathrm{ng} / \mathrm{mL}$ MMP-13 inhibitor for 14 days $(\mathrm{n}=8-12$ explants per treatment group). The bars indicate the mean + standard error.

38]. In particular, IL-1 can suppress matrix synthesis and increase enzymatic degradation in joint tissues. Physiologically relevant concentrations of IL-1 prevent the integrative repair of meniscal lesions and increase the activity of MMPs [41, 58]. This increased MMP activity contributes to $37 \%$ of the variability in meniscal shear strength of repair [58]. In turn, injury or loss of meniscal tissue is associated with degenerative changes that ultimately lead to OA [13, 29, 37, 49, 60]. Clinical treatments are needed that can promote healing of meniscal lesions in an inflammatory microenvironment. Therefore, we tested the hypotheses that inhibition of MMPs in the presence of IL-1 would decrease the activity of MMPs, increase the integrative shear strength of repair, and enhance tissue repair in the interface of meniscal lesions.

We note several limitations in our study. We chose to control for animal tissue variability rather than randomizing the treatment groups. The study design included at least seven different menisci in each treatment group and randomization in the site of harvest to each treatment group. Although the data reveal MMPs are important in preventing IL-1-mediated degradation in the meniscus, they do not delineate which MMPs are responsible for inhibition of repair. As there is no MMP-1-specific inhibitor commercially available, it was not possible to adequately analyze the role of this enzyme in meniscal healing. However, as MMP-1 is inhibited by GM 6001 and is the only enzyme for which a specific inhibitor could not be tested, our data are consistent with the possibility MMP-1 upregulation by IL-1 ultimately is responsible for preventing repair in the meniscal repair model system. We assessed repair after 14 days in culture and did not perform a time course in this study as there was no effect of the individual inhibitors at Day 14. Furthermore, the MMP inhibitors immediately inhibit the MMPs on addition to the culture media, so damage attributable to the MMPs is halted on addition of the inhibitors. MMP activity increases during the first 12 days in culture but then stabilizes [58], so longer times in culture likely would fail to yield additional insight into 


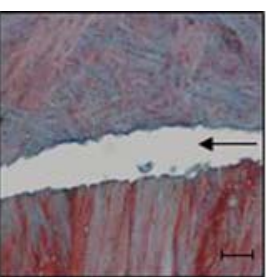

Day 0

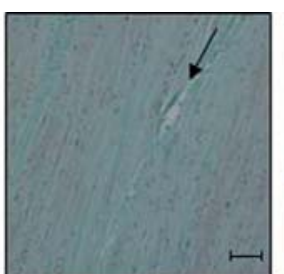

Control

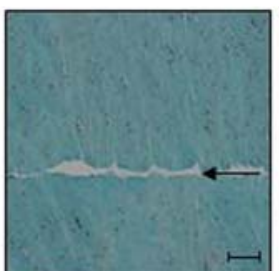

IL-1 + MMP2 Inh

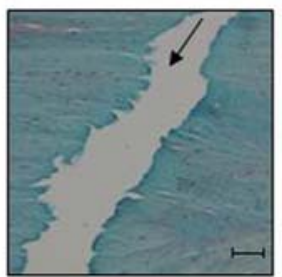

IL-1 + MMP3 Inh

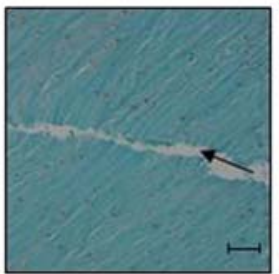

IL-1 + MMP13 Inh

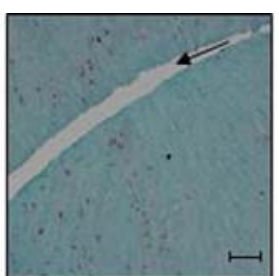

IL-1

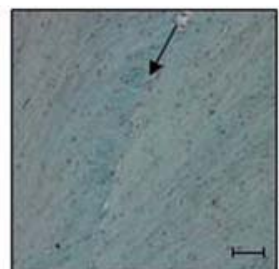

MMP2 Inh

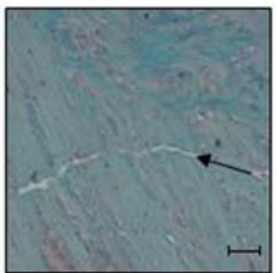

MMP3 Inh

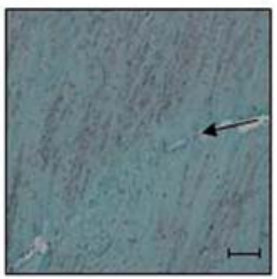

MMP13 Inh

Fig. 9 GM 6001 enhances tissue repair in the meniscal interface in the presence of IL-1. Paraffin-embedded sections of meniscal repair model explants were stained with hematoxylin to identify the cell nuclei, fast green (green) to stain the collagen fibers, and safranin $\mathrm{O}$

the role of MMPs in meniscal healing. Additionally, the MMP activity assay used in the current study does not detect proMMPs that have the potential of becoming activated later. As the assay was performed on the media, the contribution of membrane- or extracellular matrix-bound MMPs to the total MMP activity could not be determined.

Given these factors, the total MMP activity in our meniscal repair model system may be higher than that measured in this study. Several studies have shown IL-1 treatment of articular cartilage and chondrocytes upregulates proMMPs and, with addition of either plasmin or plasminogen, the collagenases are activated [15, 43, 50]. However, IL-1 treatment also upregulates the expression of urokinase plasminogen activator [43] and suppresses the expression of plasminogen activator inhibitor-1 in chondrocytes [10], resulting in an environment that favors MMP activation.

Our data showing complete inhibition of MMP activity with the broad-spectrum MMP inhibitor GM 6001, which

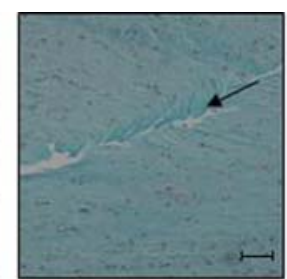

IL-1 + GM 6001

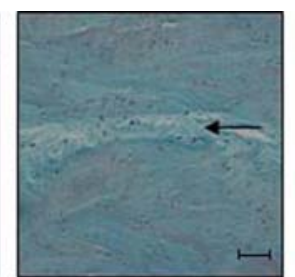

GM 6001

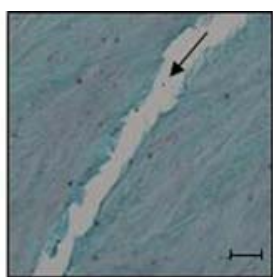

IL-1 + NC GM 6001

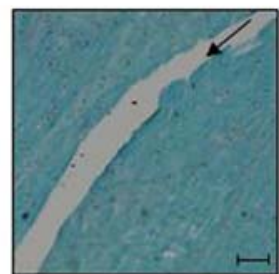

IL-1 + MMP2/9 Inh

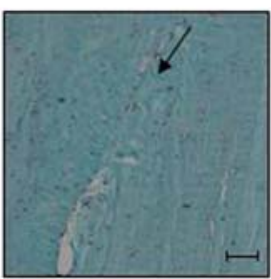

MMP2/9 Inh

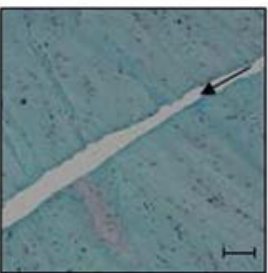

IL-1 + MMP8 Inh

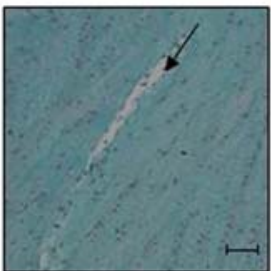

MMP8 Inh

(red) to stain the proteoglycans. Arrows mark the interface of the inner core and outer ring on all images. All treatment groups show explants cultured for 14 days. Representative images for each treatment are shown. The scale bar is equal to $100 \mu \mathrm{m}$.

blocks MMP-1, MMP-2, MMP-3, MMP-8, and MMP-9, suggest one or more of these MMPs are responsible for the increased MMP activity in IL-1-treated meniscal explants. However, suppression of MMP activity on inhibition of MMP-3 and MMP-8 suggests these individual enzymes are not responsible for preventing the repair of meniscal lesions, as this decrease in MMP activity was not concomitant with an increase in interfacial shear strength. The slight increase in MMP activity in control samples may be attributable to the explant harvesting procedures. However, all samples went through identical harvesting procedures, so the baseline MMP activity in all samples should be the same. A previous study of meniscus explants showed IL-1stimulated fibrocartilage degradation is mediated by MMPs and not aggrecanases [57]. However, it is possible the aggrecanases play a larger role in meniscal healing than is observed in IL-1-stimulated explant culture. In addition to MMPs and aggrecanases, other degradative enzymes also 
may be involved in preventing meniscal repair in an inflammatory microenvironment (eg, cathepsin B, cathepsin $\mathrm{K}$, hyaluronidase, and/or others [31, 56]).

In the presence of IL-1, the broad-spectrum MMP inhibitor GM 6001 was able to restore $52 \%$ of the interfacial shear strength lost attributable to IL-1. Inhibitors of individual MMPs (MMP-2, MMP-3, MMP-8, MMP-2/9, and MMP-13) did not enhance healing of the meniscal repair model explants. Failure of the specific MMP inhibitors alone to enhance repair suggests some MMP activity is likely necessary to promote repair, possibly allowing cells to migrate through the extracellular matrix to the repair site. This idea is consistent with a previous study of integrative cartilage repair showing collagenase treatment increases chondrocyte density in the wound edge and improves integration of the lesion edges [9]. However, as the MMPs are redundant in activity [28], inhibition of several different MMPs may be necessary to observe a measurable effect on meniscal healing. Therefore, multiple MMPs could be preventing the repair of meniscal lesions in the presence of IL-1. These results are consistent with results in a previous study, which showed $37 \%$ of the variability in the shear strength of repair is attributable to MMP activity [58]. However, our finding that inhibitors of MMPs alone are not sufficient to completely overcome the destructive effects of IL-1 suggests additional targets or combination treatments may be required to block the degradative effects of inflammation.

In the presence of IL-1, tissue repair in the interface was enhanced by inclusion of the broad-spectrum MMP inhibitor GM 6001. The increase in tissue accumulation in the interface in this sample was reflected by an increase in the shear strength of integrative repair as well. However, GM 6001 was not able to completely overcome the inhibition of tissue repair by IL-1, presumably owing to the diminished cellular accumulation and collagen deposition in the interface, as compared with control and GM 6001 alone. Given that blocking the MMPs, and thus the degradation of the extracellular matrix, was not sufficient to reverse the full effects of IL-1, perhaps promoting the synthesis of new extracellular matrix components may help to enhance the integrative repair process. In a cartilage repair model system, the strength of repair is positively correlated with collagen deposition [17] and cross-linking $[2,18]$. Thus, factors that increase collagen synthesis and decrease MMP activity likely would benefit meniscal repair. For example, transforming growth factor- $\beta 1$ increases the interfacial shear strength of repair and decreases MMP activity in the media of meniscal repair model explants [40]. Therefore, anabolic growth factor combinations may be necessary to enhance repair under inflammatory conditions. Alternatively, mechanical loading regimens may help integrative meniscal repair. In meniscal explants, static loading decreases biosynthesis of matrix components [30] and increases expression of MMPs [52]. Conversely, dynamic compression or stretch increase matrix biosynthesis $[20,51]$ and can decrease the inflammatory effects of IL-1 on isolated meniscal cells by blocking MMP-13 mRNA upregulation [21]. Ultimately, a combination of MMP inhibition, anabolic growth factors, and/or physical factors, such as mechanical loading, probably will be most beneficial for enhancing integrative meniscal repair.

These results indicate MMPs are major players in mediating the effects of IL-1 during meniscal healing. Our data suggest inhibition of MMPs can enhance the repair of meniscal lesions in an inflammatory microenvironment. Unlike inhibitors that target the inflammatory cytokine signaling pathways, transcription factors, or the plasminogen-activating pathway, inhibition of MMPs should not affect various other downstream signaling processes. In animal models of OA, MMP inhibitors can prevent cartilage degradation and joint damage [31]. However, in clinical trials, oral administration of PG-116800 (a broadspectrum MMP inhibitor with high affinity for MMP-2, MMP-3, MMP-8, MMP-9, MMP-13, and MMP-14) showed adverse musculoskeletal effects, such as arthralgia, fibrosis, or contracture [36]. However, local administration of MMP inhibitors for meniscal repair procedures should minimize any toxicities. These studies suggest intraarticular delivery of MMP inhibitors may provide a potential method to enhance meniscal repair in vivo after a meniscal injury.

Acknowledgments We thank Rebecca Wilusz for technical assistance and Franklin Moutos for assistance with manuscript preparation.

\section{References}

1. Ahmed AM, Burke DL. In-vitro measurement of static pressure distribution in synovial joints-Part I: Tibial surface of the knee. J Biomech Eng. 1983;105:216-225.

2. Ahsan T, Lottman LM, Harwood F, Amiel D, Sah RL. Integrative cartilage repair: Inhibition by beta-aminopropionitrile. J Orthop Res. 1999; 17:850-857.

3. Arnoczky SP, Warren RF. Microvasculature of the human meniscus. Am J Sports Med. 1982;10:90-95.

4. Arnoczky SP, Warren RF. The microvasculature of the meniscus and its response to injury: an experimental study in the dog. Am J Sports Med. 1983;11:131-141.

5. Baker BS, Lubowitz J. Meniscus injuries. Available at: http:// www.emedicine.com/sports/TOPIC160.HTM. Accessed August 28, 2007.

6. Billinghurst RC, Dahlberg L, Ionescu M, Reiner A, Bourne R, Rorabeck C, Mitchell P, Hambor J, Diekmann O, Tschesche H, Chen J, Van Wart H, Poole AR. Enhanced cleavage of type II collagen by collagenases in osteoarthritic articular cartilage. J Clin Invest. 1997;99:1534-1545. 
7. Bluteau G, Conrozier T, Mathieu P, Vignon E, Herbage D, Mallein-Gerin F. Matrix metalloproteinase-1, -3, -13 and aggrecanase- 1 and -2 are differentially expressed in experimental osteoarthritis. Biochim Biophys Acta. 2001;1526:147-158.

8. Borkakoti N. Structural studies of matrix metalloproteinases. J Mol Med. 2000;78:261-268.

9. Bos PK, DeGroot J, Budde M, Verhaar JA, van Osch GJ. Specific enzymatic treatment of bovine and human articular cartilage: implications for integrative cartilage repair. Arthritis Rheum. 2002;46:976-985.

10. Campbell IK, Last K, Novak U, Lund LR, Hamilton JA. Recombinant human interleukin-1 inhibits plasminogen activator inhibitor-1 (PAI-1) production by human articular cartilage and chondrocytes. Biochem Biophys Res Commun. 1991;174:251257.

11. Cao M, Stefanovic-Racic M, Georgescu HI, Miller LA, Evans $\mathrm{CH}$. Generation of nitric oxide by lapine meniscal cells and its effect on matrix metabolism: stimulation of collagen production by arginine. J Orthop Res. 1998;16:104-111.

12. Cheung HS. Distribution of type I, II, III and V in the pepsin solubilized collagens in bovine menisci. Connect Tissue Res. 1987;16:343-356.

13. Christoforakis J, Pradhan R, Sanchez-Ballester J, Hunt N, Strachan RK. Is there an association between articular cartilage changes and degenerative meniscus tears? Arthroscopy. 2005;21:1366-1369.

14. Chu SC, Yang SF, Lue KH, Hsieh YS, Li TJ, Lu KH. Naproxen, meloxicam and methylprednisolone inhibit urokinase plasminogen activator and inhibitor and gelatinases expression during the early stage of osteoarthritis. Clin Chim Acta. 2008;387:90-96.

15. Cruwys SC, Davies DE, Pettipher ER. Co-operation between interleukin-1 and the fibrinolytic system in the degradation of collagen by articular chondrocytes. $\mathrm{Br} \quad J$ Pharmacol. 1990;100:631-635.

16. Deng SJ, Bickett DM, Mitchell JL, Lambert MH, Blackburn RK, Carter HL 3rd, Neugebauer J, Pahel G, Weiner MP, Moss ML. Substrate specificity of human collagenase 3 assessed using a phage-displayed peptide library. J Biol Chem. 2000;275:3142231427.

17. DiMicco MA, Sah RL. Integrative cartilage repair: adhesive strength is correlated with collagen deposition. J Orthop Res. 2001;19:1105-1112.

18. DiMicco MA, Waters SN, Akeson WH, Sah RL. Integrative articular cartilage repair: dependence on developmental stage and collagen metabolism. Osteoarthritis Cartilage. 2002;10: 218-225.

19. Eyre DR, Muir H. The distribution of different molecular species of collagen in fibrous, elastic and hyaline cartilages of the pig. Biochem J. 1975;151:595-602.

20. Fermor B, Jeffcoat D, Hennerbichler A, Pisetsky DS, Weinberg JB, Guilak F. The effects of cyclic mechanical strain and tumor necrosis factor alpha on the response of cells of the meniscus. Osteoarthritis Cartilage. 2004;12:956-962.

21. Ferretti M, Madhavan S, Deschner J, Rath-Deschner B, Wypasek E, Agarwal S. Dynamic biophysical strain modulates proinflammatory gene induction in meniscal fibrochondrocytes. Am J Physiol Cell Physiol. 2006;290:C1610-C1615.

22. Fujita Y, Hara Y, Nezu Y, Schulz KS, Tagawa M. Proinflammatory cytokine activities, matrix metalloproteinase-3 activity, and sulfated glycosaminoglycan content in synovial fluid of dogs with naturally acquired cranial cruciate ligament rupture. Vet Surg. 2006;35:369-376.

23. Hellio Le Graverand MP, Ou Y, Schield-Yee T, Barclay L, Hart D, Natsume T, Rattner JB. The cells of the rabbit meniscus: their arrangement, interrelationship, morphological variations and cytoarchitecture. J Anat. 2001;198:525-535.
24. Hennerbichler A, Moutos FT, Hennerbichler D, Weinberg JB, Guilak F. Interleukin-1 and tumor necrosis factor alpha inhibit repair of the porcine meniscus in vitro. Osteoarthritis Cartilage. 2007; $15: 1053-1060$.

25. Hennerbichler A, Moutos FT, Hennerbichler D, Weinberg JB, Guilak F. Repair response of the inner and outer regions of the porcine meniscus in vitro. Am J Sports Med. 2007;35:754-762.

26. Hoberg M, Uzunmehmetoglu G, Sabic L, Reese S, Aicher WK, Rudert M. [Characterisation of human meniscus cells] [in German]. Z Orthop Ihre Grenzgeb. 2006;144:172-178.

27. Hopkins SJ, Humphreys M, Jayson MI. Cytokines in synovial fluid I: The presence of biologically active and immunoreactive IL-1. Clin Exp Immunol 1988;72:422-427.

28. Hu J, Van den Steen PE, Sang QX, Opdenakker G. Matrix metalloproteinase inhibitors as therapy for inflammatory and vascular diseases. Nat Rev Drug Discov. 2007;6:480-498.

29. Hunter DJ, Zhang YQ, Niu JB, Tu X, Amin S, Clancy M, Guermazi A, Grigorian M, Gale D, Felson DT. The association of meniscal pathologic changes with cartilage loss in symptomatic knee osteoarthritis. Arthritis Rheum. 2006;54:795-801.

30. Imler SM, Doshi AN, Levenston ME. Combined effects of growth factors and static mechanical compression on meniscus explant biosynthesis. Osteoarthritis Cartilage. 2004;12:736-744.

31. Janusz MJ, Bendele AM, Brown KK, Taiwo YO, Hsieh L, Heitmeyer SA. Induction of osteoarthritis in the rat by surgical tear of the meniscus: inhibition of joint damage by a matrix metalloproteinase inhibitor. Osteoarthritis Cartilage. 2002;10: 785-791.

32. Kahle P, Saal JG, Schaudt K, Zacher J, Fritz P, Pawelec G. Determination of cytokines in synovial fluids: correlation with diagnosis and histomorphological characteristics of synovial tissue. Ann Rheum Dis. 1992;51:731-734.

33. Kambic HE, McDevitt CA. Spatial organization of types I and II collagen in the canine meniscus. J Orthop Res. 2005;23:142-149.

34. Knauper V, Cowell S, Smith B, Lopez-Otin C, O'Shea M, Morris $\mathrm{H}$, Zardi L, Murphy G. The role of the c-terminal domain of human collagenase-3 (MMP-13) in the activation of procollagenase-3, substrate specificity, and tissue inhibitor of metalloproteinase interaction. J Biol Chem. 1997;272:7608-7616.

35. Knauper V, Lopez-Otin C, Smith B, Knight G, Murphy G. Biochemical characterization of human collagenase-3. J Biol Chem. 1996;271:1544-1550.

36. Krzeski P, Buckland-Wright C, Balint G, Cline GA, Stoner K, Lyon R, Beary J, Aronstein WS, Spector TD. Development of musculoskeletal toxicity without clear benefit after administration of PG-116800, a matrix metalloproteinase inhibitor, to patients with knee osteoarthritis: a randomized, 12-month, double-blind, placebo-controlled study. Arthritis Res Ther. 2007;9:R109.

37. Lohmander LS, Roos H, Dahlberg L, Hoerrner LA, Lark MW. Temporal patterns of stromelysin-1, tissue inhibitor, and proteoglycan fragments in human knee joint fluid after injury to the cruciate ligament or meniscus. J Orthop Res. 1994;12:21-28.

38. Lotz M. Cytokines in cartilage injury and repair. Clin Orthop Relat Res. 2001;391(suppl):S108-S115.

39. Markolf KL, Bargar WL, Shoemaker SC, Amstutz HC. The role of joint load in knee stability. J Bone Joint Surg Am. 1981;63:570-585.

40. McNulty AL, Guilak F. Integrative repair of the meniscus: lessons from in vitro studies. Biorheology. 2008;45:487-500.

41. McNulty AL, Moutos FT, Weinberg JB, Guilak F. Enhanced integrative repair of the porcine meniscus in vitro by inhibition of interleukin-1 or tumor necrosis factor alpha. Arthritis Rheum. 2007;56:3033-3042.

42. Mengshol JA, Mix KS, Brinckerhoff CE. Matrix metalloproteinases as therapeutic targets in arthritic diseases: bull's-eye or missing the mark? Arthritis Rheum. 2002;46:13-20. 
43. Milner JM, Elliott SF, Cawston TE. Activation of procollagenases is a key control point in cartilage collagen degradation: interaction of serine and metalloproteinase pathways. Arthritis Rheum. 2001;44:2084-2096.

44. Mitchell PG, Magna HA, Reeves LM, Lopresti-Morrow LL, Yocum SA, Rosner PJ, Geoghegan KF, Hambor JE. Cloning, expression, and type ii collagenolytic activity of matrix metalloproteinase-13 from human osteoarthritic cartilage. J Clin Invest. 1996;97:761-768.

45. Nagase H, Woessner JF, Jr. Matrix metalloproteinases. J Biol Chem. 1999;274:21491-21494.

46. Ohuchi E, Imai K, Fujii Y, Sato H, Seiki M, Okada Y. Membrane type 1 matrix metalloproteinase digests interstitial collagens and other extracellular matrix macromolecules. J Biol Chem. 1997;272:2446-2451.

47. Rasmussen FH, Yeung N, Kiefer L, Murphy G, Lopez-Otin C, Vitek MP, Moss ML. Use of a multiple-enzyme/multiple-reagent assay system to quantify activity levels in samples containing mixtures of matrix metalloproteinases. Biochemistry. 2004;43:2987-2995.

48. Reboul P, Pelletier JP, Tardif G, Cloutier JM, Martel-Pelletier J. The new collagenase, collagenase- 3 , is expressed and synthesized by human chondrocytes but not by synoviocytes: a role in osteoarthritis. J Clin Invest. 1996;97:2011-2019.

49. Roos H, Lauren M, Adalberth T, Roos EM, Jonsson K, Lohmander LS. Knee osteoarthritis after meniscectomy: prevalence of radiographic changes after twenty-one years, compared with matched controls. Arthritis Rheum. 1998;41:687-693.

50. Saito S, Katoh M, Masumoto M, Matsumoto S, Masuho Y. Collagen degradation induced by the combination of IL-1alpha and plasminogen in rabbit articular cartilage explant culture. J Biochem. 1997;122:49-54.

51. Shin SJ, Fermor B, Weinberg JB, Pisetsky DS, Guilak F. Regulation of matrix turnover in meniscal explants: role of mechanical stress, interleukin-1, and nitric oxide. J Appl Physiol. 2003;95:308-313.
52. Upton ML, Chen J, Guilak F, Setton LA. Differential effects of static and dynamic compression on meniscal cell gene expression. J Orthop Res. 2003;21:963-969.

53. Upton ML, Chen J, Setton LA. Region-specific constitutive gene expression in the adult porcine meniscus. $J$ Orthop Res. 2006;24:1562-1570.

54. van den Berg WB, Joosten LA, van de Loo FA. TNF alpha and IL-1 beta are separate targets in chronic arthritis. Clin Exp Rheumatol. 1999;17(6 suppl 18):S105-S114.

55. Vankemmelbeke M, Dekeyser PM, Hollander AP, Buttle DJ, Demeester J. Characterization of helical cleavages in type II collagen generated by matrixins. Biochem J. 1998;330(pt 2):633640.

56. Wilson CG, Palmer AW, Zuo F, Eugui E, Wilson S, Mackenzie R, Sandy JD, Levenston ME. Selective and non-selective metalloproteinase inhibitors reduce IL-1-induced cartilage degradation and loss of mechanical properties. Matrix Biol. 2007;26:259-268.

57. Wilson CG, Zuo F, Sandy JD, Levenston ME. Inhibition of MMPs, but not of ADAMTS-4 and -5, reduces IL- 1 stimulated fibrocartilage degradation. Trans Orthop Res Soc. 2006;31: 0031.

58. Wilusz RE, Weinberg JB, Guilak F, McNulty AL. Inhibition of integrative repair of the meniscus following acute exposure to interleukin-1 in vitro. J Orthop Res. 2008;26:504-512.

59. Wojtys EM, Chan DB. Meniscus structure and function. Instr Course Lect. 2005;54:323-330.

60. Wyland DJ, Guilak F, Elliott DM, Setton LA, Vail TP. Chondropathy after meniscal tear or partial meniscectomy in a canine model. J Orthop Res. 2002;20:996-1002.

61. Yang SF, Hsieh YS, Lue KH, Chu SC, Chang IC, Lu KH. Effects of nonsteroidal anti-inflammatory drugs on the expression of urokinase plasminogen activator and inhibitor and gelatinases in the early osteoarthritic knee of humans. Clin Biochem. 2008;41:109-116. 